
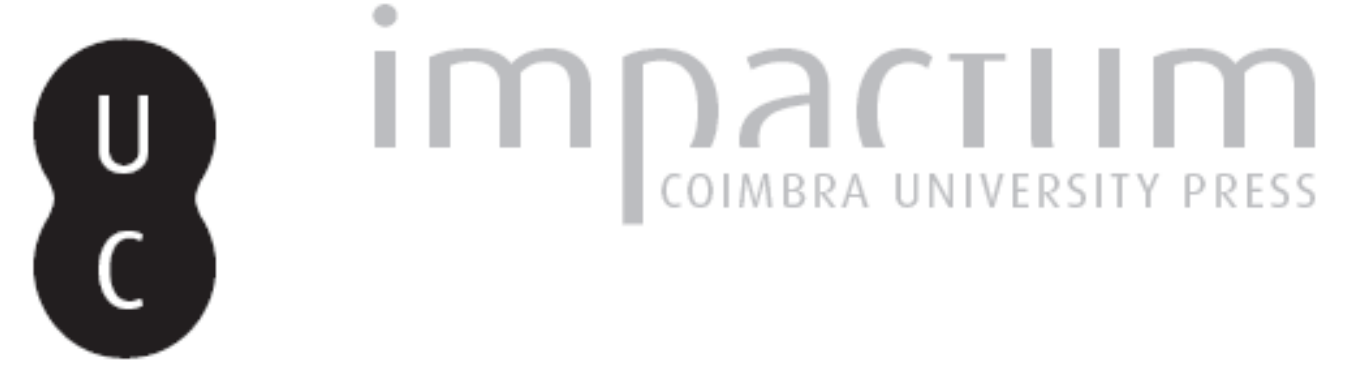

\title{
Cartografia de suscetibilidade a deslizamentos e unidades territoriais de risco à escala regional: o caso da região Figueira da Foz - Nazaré
}

\author{
Autor(es): $\quad$ Ramos, Anabela; Cunha, Lúcio; Cunha, Pedro P.; Freitas, M. Isabel \\ Castreghini
}

Publicado por: Faculdade de Letras da Universidade de Coimbra, Departamento de

URL

persistente: URI:http://hdl.handle.net/10316.2/30281

DOI: $\quad$ DOI:http://dx.doi.org/10.14195/0871-1623_31_24

Accessed : $\quad$ 26-Apr-2023 05:43:12

A navegação consulta e descarregamento dos títulos inseridos nas Bibliotecas Digitais UC Digitalis, UC Pombalina e UC Impactum, pressupõem a aceitação plena e sem reservas dos Termos e Condições de Uso destas Bibliotecas Digitais, disponíveis em https://digitalis.uc.pt/pt-pt/termos.

Conforme exposto nos referidos Termos e Condições de Uso, o descarregamento de títulos de acesso restrito requer uma licença válida de autorização devendo o utilizador aceder ao(s) documento(s) a partir de um endereço de IP da instituição detentora da supramencionada licença.

Ao utilizador é apenas permitido o descarregamento para uso pessoal, pelo que o emprego do(s) título(s) descarregado(s) para outro fim, designadamente comercial, carece de autorização do respetivo autor ou editor da obra.

Na medida em que todas as obras da UC Digitalis se encontram protegidas pelo Código do Direito de Autor e Direitos Conexos e demais legislação aplicável, toda a cópia, parcial ou total, deste documento, nos casos em que é legalmente admitida, deverá conter ou fazer-se acompanhar por este aviso.

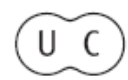




\title{
Cartografia de suscetibilidade a deslizamentos e unidades territoriais de risco à escala regional: o caso da região Figueira da Foz - Nazaré
}

\author{
Anabela Ramos \\ Centro de Estudos de Geografia e Ordenamento do Território. Faculdade de Letras da Universidade de Coimbra. \\ ana-baia@sapo.pt

\section{Lúcio Cunha} \\ Centro de Estudos de Geografia e Ordenamento do Território. Faculdade de Letras da Universidade de Coimbra. \\ luciogeo@ci.uc.pt
}

\section{Pedro P. Cunha}

Departamento de Ciências da Terra, IMAR-CMA, Universidade da Coimbra pcunha@dct.ci.uc.pt

\section{Isabel Castreghini Freitas}

Departamento de Planejamento Territorial e Geoprocessamento - IGCE. UNESP (Campus de Rio Claro). ifreitas@rc.unesp.br

\section{Resumo:}

Este trabalho faz uma análise da suscetibilidade a deslizamentos na área da plataforma litoral entre a Figueira da Foz e a Nazaré. Pretende-se efetuar uma cartografia de suscetibilidade, pelo método de análise hierárquica de pares, que constitua um instrumento para o ordenamento do território e para a gestão de risco, permitindo definir áreas prioritárias para estudos de pormenor.

Poderemos enunciar, para a área estudada, diferentes tipos de processos perigosos naturais: sismos, erosão litoral, inundações, incêndios florestais, movimentos de massa (deslizamentos, desabamentos e fluxos). Estes afetam desigualmente as diferentes unidades territoriais, tendo por base as suas características físicas e de uso dos solos: Serras calcárias, Colinas gresosas, Planícies aluviais, Campo dunar eólico, Faixa litoral, Corredores neotectónicos (alinhamentos tectónicos e núcleos diapíricos).

Palavras-chave: Plataforma litoral. Riscos naturais. Territórios de risco. Deslizamentos. Mapas de suscetibilidade.

\section{Resumé:}

Cartographie de susceptibilité à glissements et unités territoriales de risque à l'échelle regional: le cas d'étude Figueira da Foz - Nazaré.

Ce travail porte sur l'analyse de la susceptibilité à glissements de terrain dans la plateforme côtière entre Figueira da Foz et Nazaré. On veux faire une cartographie de la susceptibilité à glissement, par la méthode d'analyse hiérarchique de pairs, qui constitue un outil important pour la planification et la gestion des risques, ce qui permet de définir des domaines prioritaires pour des études détaillées.

Nous pouvons énoncer, dans la région étudiée, différents types de processes dangeroux naturels : sismes, l'érosion côtière, inondations, incendies, glissements de terrain, coulées de boue et des flux qui affectent inégalement les diverses unités territoriales du risque, fondée sur les caractéristiques physiques et l'utilisation des terres: collines calcaires, collines greseuses, plaines alluviaux, champ des dunes, zone côtière, zones de alignements neotectoniques.

Mots-clés: Plateforme côtiére. Risques natureles. Territoires de risque. Glissements de terrain. Cartes de susceptibilité. 


\section{Abstract:}

Landslide cartographic susceptibility and hazard landscape units in a regional scale: the case stude of Figueira da Foz - Nazaré region

The coastal plain located betwen Figueira da Foz and Nazaré (western Portugal) has a general low slope towards west, presents elevations below $200 \mathrm{~m}$ a.s.l. and constitutes an important geomophological unit in this area. Towards north, east and south the platform is limited by the limestone relieves of the Serra da Boa Viagem - Verride arc, Sicó Massif and Estremenho Massif, respectivelly. These relieves are characterized by high slope values and also higher altitudes (> $200 \mathrm{~m}$ ). The area comprises the terminal portion of the hydrographic basins of the Mondego and Lis rivers. Regionally six territorial units were distinguished which, given the characteristics of natural systems and the development of human activities, determine different areas of risk: the limestone hills, the sandy hills, floodplains, coastal plain the coastline and the probable neotectonic structures. The limestone hills are particularly sensitive to mass movements (mainly landslides), the sandy hills are vulnerable not only to movements and fluvial erosion, but also to forest fires. Alluvial plains are vulnerable to floods and overflooding, coastal plain and its eolian dune field could be very vulnerable to forest fires, the coastline presents high vulnerability to erosion of different types according to morphology of the coast and, finally, the active tectonic structures, particularly those that are related with diapirs, are a source of seismic risk.

It is our goal with this study, to create a GIS project covering diverse thematic mapping (lithologies, tectonics, slopes, hydrology, land use), to do data spatial analysis, particularly in anticipation of the hypothetical scenarios of rising sea level, floods, forest fires and slope movements.

Key-words: Coastal plain. Natural risks. Risks áreas. Landslides. Susceptibility maps.

\section{Introdução}

Dada a crescente relevância científica, mediática, política, económica e social dos riscos naturais para a sociedade, tem todo o interesse a adoção de estratégias de atuação, nomeadamente de mecanismos de precaução e medidas de prevenção, capazes de minimizar perdas e danos económicos e sociais, à escala regional.

Este trabalho diz respeito à análise da suscetibilidade a deslizamentos na área da "Plataforma Litoral" (FERREIRA, 1978) e relevos calcários enquadrantes, entre a Figueira da Foz e a Nazaré (Figura 1A). Respetivamente a norte, a leste e a sul, a Plataforma Litoral é limitada pelos relevos calcários do arco Serra da Boa Viagem - Verride e dos Maciços de Sicó e Estremenho. 0 encaixe da rede hidrográfica durante o Quaternário determinou a existência de importantes vales, que na área de estudo compreendem os setores terminais das bacias hidrográficas dos rios Mondego e Lis.

Pretende-se efetuar uma cartografia de suscetibilidade, para ulteriormente se integrar na de risco natural à escala regional, já que esta constitui um instrumento importante para o ordenamento do território e gestão do socorro e emergência, permitindo definir áreas prioritárias para estudos de pormenor.

A esta escala é possivel distinguir diferentes unidades territoriais de risco que resultam da integração dinâmica de componentes relativamente homogéneos de suporte e cobertura, compreendendo elementos fí- sicos (geológicos, pedológicos, geomorfológicos e climáticos), biológicos (vegetação) e antrópicos (uso do solo; sistemas socioeconómicos). Estes elementos são fundamentais no processo de análise e avaliação de risco, uma vez que os seus elementos constituintes atuam como fatores determinantes das equações da suscetibilidade e do risco.

Uma das formas de avaliar a suscetibilidade é por meio do cálculo de índices que têm a função de simplificar, quantificar e expressar fenómenos complexos a partir da agregação de dados e informações quantitativas de cada um deles, que tem como resultado um conjunto de parâmetros associados por meio de uma relação pré-estabelecida que dá origem a um novo e único valor.

Ao utilizar Sistemas de Informação Geográfica (SIG's), a metodologia seguida é adequada para apoiar as mais diferentes tarefas de planeamento, permitindo o trabalho com grande volume de dados a diferentes escalas. Constitui, assim, um instrumento valioso na cartografia e análise de suscetibilidade e risco, favorecendo o conhecimento e caracterização de situações ou fenómenos que ocorrem espacialmente. Os SIG's permitem análises espaciais complexas, a partir do tratamento de dados geográficos e seus atributos inseridos em bases de dados.

Poderemos enunciar, para a área estudada, diferentes tipos de processos perigosos naturais: sismos, erosão litoral, inundações, incêndios florestais, movimentos de massas (deslizamentos, desabamentos e flu- 
xos), que afetam desigualmente as diferentes unidades territoriais de risco, tendo por base as características físicas e de uso dos solos: Serras calcárias, Colinas areníticas, Planícies aluviais, Campo dunar eólico, Faixa litoral, Corredores neotectónicos (alinhamentos tectónicos e núcleos diapíricos). Neste trabalho pretende-se discutir um modelo de susceptibilidade a deslizamentos construído para este espaço, como contributo para a definição de territórios de risco diferenciados.

\section{A área de estudo}

A área de estudo insere-se na bordadura atlântica definida pelos paralelos do Cabo Mondego e da Nazaré (Figura 1A), onde afloram unidades sedimentares com idades compreendidas entre o Triásico e o Holocénico, compostas por rochas siliciclásticas e carbonatadas, e, em afloramentos muito circunscritos, algumas rochas ígneas (Figura 1B).

A faixa ocidental da região Figueira da Foz - Nazaré apresenta altitudes geralmente inferiores a $200 \mathrm{~m}$, sucessivamente menores para oeste. Corresponde a um conjunto de relevos com fracos declives (Figura 2) que tradicionalmente é denominada por Plataforma Litoral (FerReIRA, 1978, 1983). A interpretação corrente assume que ela representa uma superfície de agradação sedimentar com idade provável pliocénica final a plistocénica inicial, a partir da qual se terá realizado o encaixe da rede hidrográfica.

No relevo da área destaca-se topograficamente a Serra da Boa Viagem (257 m de altitude no v. g. da Bandeira) sobre a planície litoral. A sua imponência orográfica deve-se à sua constituição calcária (Figura 1B), mas também a um processo de soerguimento recente. Corresponde, actualmente, a um relevo arqueado e inclinado para sul, escalonado por vários compartimentos tectónicos que definem um abatimento progressivo para leste (Figura 3).

No sector oriental da região Figueira da Foz - Nazaré localizam-se os relevos mais elevados, com altitudes superiores a $500 \mathrm{~m}$ e declives geralmente superiores a 15\% (Figura 2), constituídos por unidades calcárias e, minoritariamente, arenosas do Jurássico e Cretácico. Estes relevos delimitam a Plataforma Litoral a leste e a sul pelos conjuntos montanhosos que constituem o Maciço do Sicó e o Maciço Calcário Estremenho (Figura 2).

Cunha $(1988,1990,1993,1997)$ definiu no Maciço do Sicó, de NE para SW, as seguintes unidades morfo-estruturais: 1) colinas dolomíticas, em faixa com orientação meridiana, onde os calcários dolomíticos e dolomias do Jurássico Inferior apresentam fraco pen-
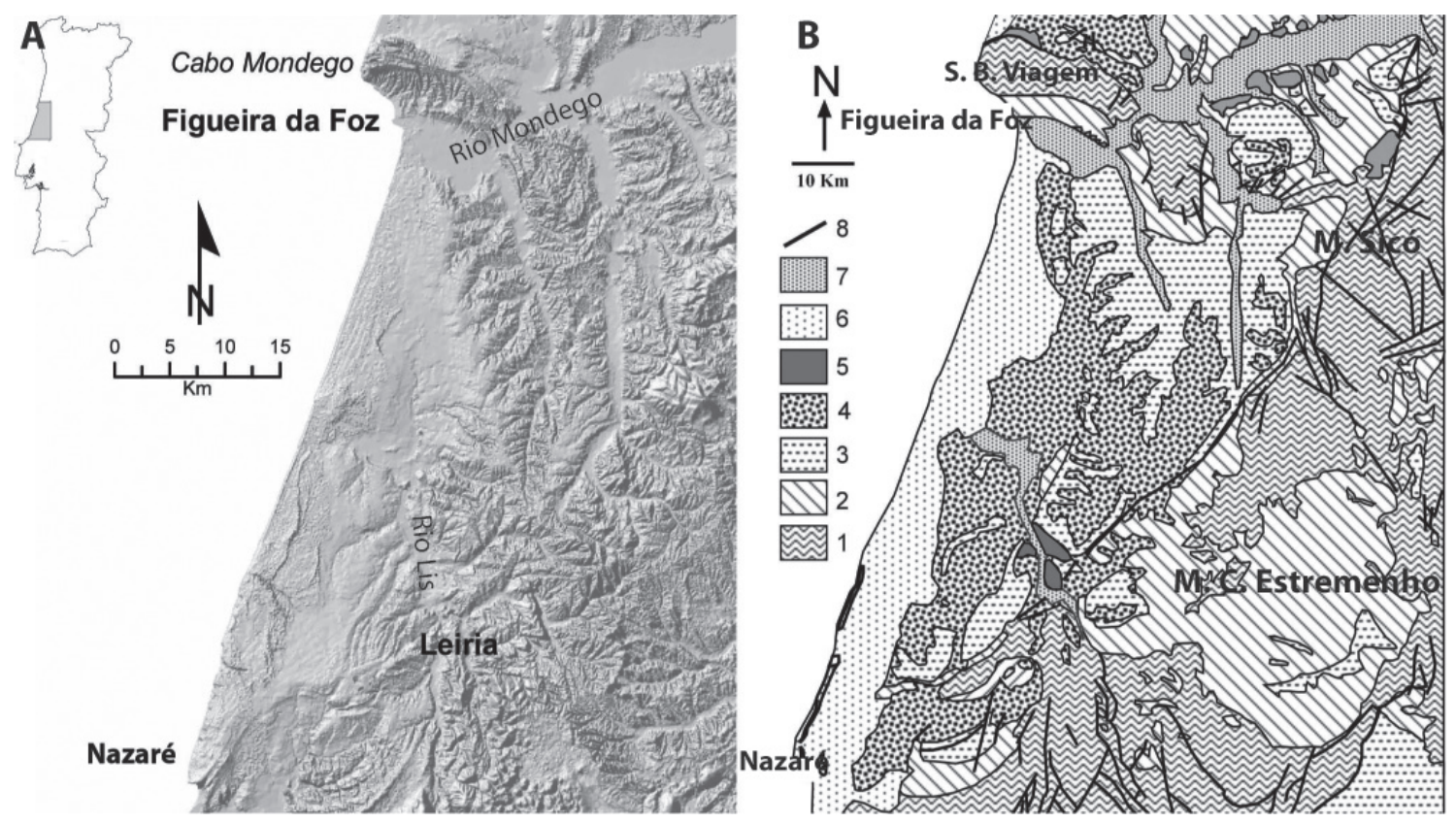

Figura 1

A - Enquadramento da área de estudo, (modelo sombreado com sobrelevação vertical de 8x); B - Mapa geológico da região Figueira da Foz - Nazaré (adaptado da Carta Geológica de Portugal, esc. 1/500000). 1 - Triásico a Jurássico, 2- Cretácico, 3 - Paleogénico a Miocénico, 4 - Pliocénico, 5 - Plistocénico (terraços), 6 - Plistocénico sup. a Holocénico (dunas), 7 - Holocénico (aluviões), 8 - Falha. 


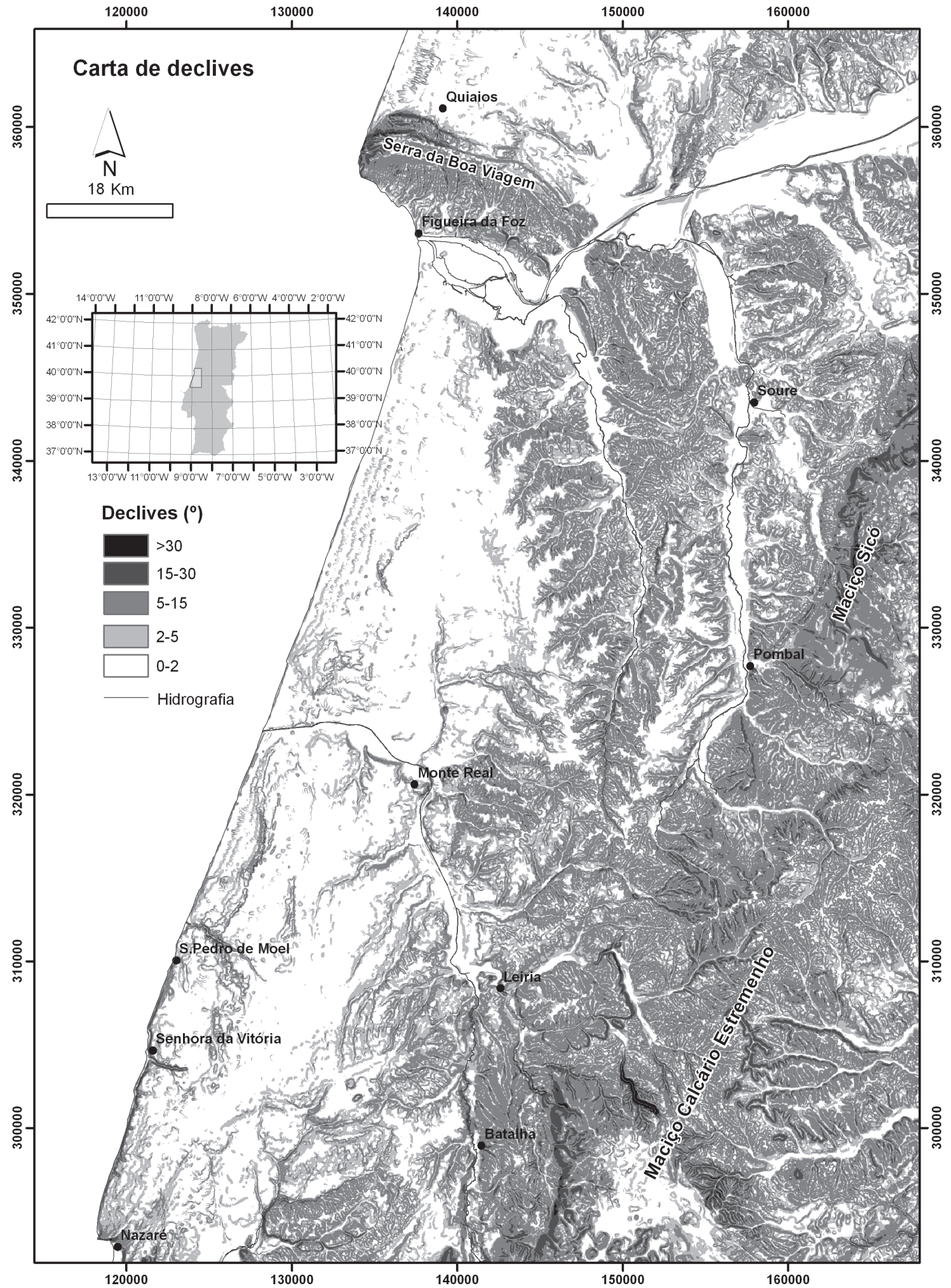

Figura 2

Mapa de declives para a região entre a Figueira da Foz e a Nazaré 
dor para oeste; 2) depressões resultantes do comportamento mais brando das formações calco-margosas do Jurássico Inferior; 3) serras calcárias que correspondem a um conjunto de serras e planaltos, modeladas em materiais do Jurássico Médio afetados por dobramentos e importantes falhas, onde o Maciço do Sicó constitui o elemento meridional do conjunto e também o relevo mais elevado (533 $\mathrm{m})$.

O Maciço Calcário Estremenho localiza-se um pouco mais a sul, formado por compartimentos soerguidos que culminam a altitudes moderadas $(680 \mathrm{~m})$. A natureza predominantemente calcária das rochas que o compõem, contribui para a sua fisionomia particular, acentuando a imponência das escarpas e o desenvolvimento de uma morfologia cársica bem característica, no entanto, o fundamental da arquitetura do Maciço é devido à tectónica (MARTINs, 1949; RodRIGUES, 2007).

Os cursos de água principais que drenam a região em estudo são o rio Mondego e o rio Lis (Figura 3).

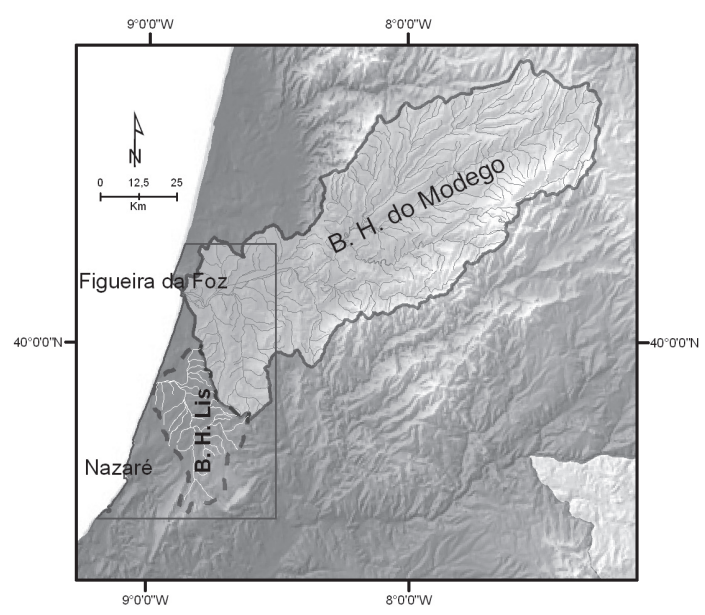

Figura 3

Bacias hidrográficas dos rios Mondego e Lis.

São vários os trabalhos realizados por diferentes autores sobre a geomorfologia desta região. ALmEIDA et al. (1990) apresentam um esboço geomorfológico simplificado do Baixo Mondego, em que definem as principais unidades geomorfológicas. ALMEIDA (1997) apresenta as principais unidades morfoestruturais com incidência na paisagem da Gândara, Quiaios e Serra da Boa Viagem e Alhadas. Na zona envolvente do estuário do rio Mondego, Ramos (2000) e Ramos et al. (2001) apresentam um esboço geomorfológico em que evidenciam a relação forma-depósito, que aplicam aos depósitos de terraço mais recentes do Mondego. Em 2002, Lúcio Cunha apresenta, nas Provas de Agregação, o Mapa Geomorfológico do Baixo Mondego. Este autor tem vindo, também, a desenvolver trabalhos que têm contribuído para o conhecimento da geomorfologia e estrutura do Maciço de Sicó (Cunha, 1988; 1990; 1993; 1997). CunHa (1990) define o Maciço de Sicó como um dos principais maciços calcários carsificados da Orla Mesocenozóica Ocidental Portuguesa e corresponde a um conjunto pouco elevado (Sicó, $553 \mathrm{~m}$; Alvaiázere, $618 \mathrm{~m}$ ) de serras e planaltos calcários que se estendem por cerca de $430 \mathrm{~km}^{2}$ a sul de Coimbra. O Maciço Calcário Estremenho (MCE) está localizado no centro de Portugal, a cerca de 20 km do Oceano Atlântico, sendo formado por compartimentos levantados que atingem altitudes moderadas (máx. $680 \mathrm{~m}$ ). Os esforços tectónicos são responsáveis pelas unidades morfoestruturais do MCE, compostas por três relevos em estrutura anticlinal: Candeeiros, Aire e Alqueidão; dois planaltos: Sto. António e S. Mamede (incluindo a Plataforma de Fátima); duas grandes depressões: Minde-Alvados e Mendiga; um alinhamento diapírico alongado entre Rio Maior e Batalha, que passa na Portela de Vale de Espinho e em Porto de Mós (RodRIGUES, 2007). Foram também efetuadas por Ramos (2008) as cartas geomorfológicas de pormenor dos estuários do Rio Mondego e Lis.

Considerando a importância da tectónica na evolução morfostrutural da área, são ainda de referir as interpretações de CABRAL e RiBeIRo (1988), CABRAL (1995) e RiBEIRO et al. (1996).

Para além dos trabalhos de geomorfologia, existem também trabalhos realizados sobre riscos naturais nesta área, uns à escala regional, outros à escala local. Sem a intenção de uma referência exaustiva a todos os estudos, referimos os de CunHa e Gonçalves (1994), Lourenço et al. (1994), Cunha et al. (1997), CUNHA e DinIs (1998), Ribeiro (2000), Rebelo (2001), Cunha (2002), Cunha e Dimuccio (2002), DRAOTC (2003), Lopes (2005, 2006), Zêzere et al. (2006), Santos (2009), André e Cordeiro (2010) e DUDF (2011).

\section{Modelo conceptual}

Para a criação de um modelo de análise de riscos naturais convém, antes de mais, que sejam esclarecidos, de forma breve, mas clara, os conceitos que the servem de base, nomeadamente, os conceitos de risco, perigosidade, susceptibilidade e vulnerabilidade, entre outros. Tratando-se de uma temática com desenvolvimento recente e de forte cariz interdisciplinar que, por isso recebe contributos de diferentes áreas científicas, impõe-se esta clarificação dos conceitos envolvidos na análise dos diferentes tipos de riscos, que está tam- 
bém bem patente, por exemplo, em Bachmann e AlLgöWER (1999), Zêzere (2000), Cunha e Dimuccio (2002) e Abreu (2007).

Aceitamos, assim, que o conceito de risco envolve a relação entre a perigosidade, que corresponde à probabilidade de ocorrência temporal (eventualidade) e espacial (suscetibilidade) de um fenómeno potencialmente danoso, e a vulnerabilidade que, num sentido muito lato, corresponde ao nível de consequências previsíveis sobre a sociedade desse fenómeno e que pode ser decomposto em três componentes principais: população exposta, valor dos bens potencialmente afetados e vulnerabilidade social.

Neste trabalho, apenas se avaliará o primeiro termo deste binómio, a perigosidade e, dentro dele, a sua componente espacial, a suscetibilidade.

De seguida define-se cada um dos conceitos utilizados no modelo conceptual que seguimos, de acordo com as propostas de JuLIão et al. (2009):

Suscetibilidade - Representa a propensão para uma área ser afetada por um determinado processo perigoso, em tempo indeterminado, sendo avaliada através dos fatores de predisposição para a ocorrência dos processos ou ações, não contemplando o seu período de retorno ou a probabilidade de ocorrência.

Perigosidade - Corresponde à probabilidade de ocorrência de um processo ou ação com potencial destruidor (ou para provocar danos) com uma determinada severidade, numa dada área e num dado período de tempo.

Vulnerabilidade - Grau de perda de um elemento ou conjunto de elementos expostos, em resultado da ocorrência de um processo perigoso.

Risco - Probabilidade de ocorrência de um processo perigoso (Perigosidade) e respetiva estimativa das suas consequências sobre pessoas e bens ou sobre o ambiente, expressas em danos corporais e/ou prejuízos materiais e funcionais, diretos ou indiretos (Vulnerabilidade).

\section{Metodologia}

Para a elaboração da carta de suscetibilidade a deslizamento seguiu-se o Método de Análise Hierárquica (AHP - Analytic Hierarchy Process). Este método criado por SAATY (1991) é um método de análise multicritério e pode ser usado na quantificação de características qualitativas, permitindo a sua ponderação. Tem sido utilizado com sucesso, por exemplo, na aplicação ao estudo da afetação potencial de usos do solo (FIGUEIREDo, 2001) ou na avaliação da suscetibilidade à erosão hídrica (CoRreia, 2007).

O método fundamenta-se em comparação das diversas características, duas a duas. A partir da construção de uma matriz quadrada (Quadro I) avalia-se a importância relativa de uma característica sobre a outra, utilizando-se para isto uma escala adequada. SAATY (1991) propõe a utilização da escala mostrada no Quadro II. Preenchida a matriz de comparação, calcula-se o autovalor e seu correspondente autovetor. 0 autovetor dá a ordem de prioridade ou hierarquia das características estudadas. Este resultado é importante para a avaliação de suscetibilidade, pois será usado para dar a importância relativa de cada característica, bem como a sua ordenação hierárquica. 0 autovalor é a medida que permitirá avaliar a consistência ou a qualidade da solução obtida. Esta é outra vantagem do método, a possibilidade de verificação da consistência.

Onde wij representa o julgamento quantificado do par de características $\mathrm{Ci}, \mathrm{Cj}$ e é definido pelas seguintes regras:

1. Se $w i j=\alpha$, então $w j i=1 / \alpha, \alpha \neq 0$;

2. Se $C_{i}$ é julgado como de igual importância relativa a $C_{j}$, então $w i j=1$, wji $=1$ e wii $=1$, para todo o i.

O vetor próprio da matriz pode ser estimado pela seguinte fórmula:

$$
W i=\left(\Pi_{j-1}^{n} w i j\right)^{1 / n}
$$

E deve ser normalizado para que o somatório dos seus elementos seja igual à unidade. Basta para isso,

Quadro I

Matriz de comparações e cálculo do vetor próprio

\begin{tabular}{|c|c|c|c|c|c|c|}
\hline Critérios & $\mathrm{C}_{1}$ & $\mathrm{C}_{2}$ & $\mathrm{C}_{3}$ & $\ldots$ & $\mathrm{C}_{\mathrm{n}}$ & $\mathrm{Wi}$ \\
\hline $\mathrm{C}_{1}$ & $1 / \Sigma \mathrm{C} 1$ & $\mathrm{~W} 21 / \Sigma \mathrm{C} 2$ & $\mathrm{~W} 31 / \Sigma \mathrm{C} 3$ & $\ldots$ & $W n 1 / \Sigma \mathrm{Cn}$ & $\Sigma \mathrm{C} 1 / \mathrm{n}$ \\
\hline $\mathrm{C}_{2}$ & $\mathrm{~W} 12 / \Sigma \mathrm{C} 1$ & $1 / \Sigma \mathrm{C} 2$ & $\mathrm{~W} 32 / \Sigma \mathrm{C} 3$ & $\ldots$ & $W n 2 / \Sigma \mathrm{Cn}$ & $\Sigma \mathrm{C} 2 / \mathrm{n}$ \\
\hline $\mathrm{C}_{3}$ & $\mathrm{~W} 13 / \Sigma \mathrm{C} 1$ & $\mathrm{~W} 23 / \Sigma \mathrm{C} 2$ & $1 / \Sigma \mathrm{C} 3$ & $\ldots$ & $W n 3 / \Sigma \mathrm{Cn}$ & $\Sigma \mathrm{C} 3 / \mathrm{n}$ \\
\hline$\ldots$ & $\ldots$ & $\ldots$ & $\ldots$ & $\ldots$ & $\ldots$ & $\ldots$ \\
\hline $\mathrm{C}_{\mathrm{n}}$ & $\mathrm{W} 1 \mathrm{n} / \Sigma \mathrm{C} 1$ & $\mathrm{~W} 2 \mathrm{n} / \Sigma \mathrm{C} 2$ & $\mathrm{~W} 3 \mathrm{n} / \Sigma \mathrm{C} 3$ & $\ldots$ & $1 / \Sigma \mathrm{Cn}$ & $\Sigma \mathrm{Cn} / \mathrm{n}$ \\
\hline & $\Sigma \mathrm{C} 1$ & $\Sigma \mathrm{CC} 2$ & $\Sigma \mathrm{C} 3$ & $\ldots$ & $\Sigma \mathrm{Cn}$ & \\
\hline
\end{tabular}


calcular a proporção de cada elemento em relação à soma.

$$
\mathrm{T}=|\mathrm{W} 1 / \Sigma \mathrm{Wi} \quad \mathrm{W} 2 / \Sigma \mathrm{Wi} \quad \ldots \mathrm{Wn} / \Sigma \mathrm{i}|
$$

Onde T é o vetor próprio normalizado e será utilizado para quantificar e ponderar a importância de cada um dos critérios.

Para testar a consistência da resposta, o que indica se os dados estão logicamente relacionados, SAATY (1977) propõe o seguinte procedimento:

$$
\lambda_{\text {máx }}=\mathrm{T} . \mathrm{W}
$$

onde $w$ é calculado pela soma das colunas da matriz de comparações.

Calcula-se, então, o Índice de consistência (IC):

$$
I C=\frac{(\lambda \max -n)}{(n-1)}
$$

A razão de consistência $(R C)$ é calculada pela equação:

$$
\mathrm{RC}=\frac{\mathrm{IC}}{\mathrm{CA}}
$$

$\mathrm{RC}$ é a razão entre IC e um índice de consistência aleatória (CA). 0 índice CA, apresentado no quadro III, é proveniente de uma amostra de 500 matrizes recíprocas positivas geradas aleatoriamente, de tamanho até 11 por 11 .

Considera-se aceitável uma razão de consistência menor que 0,10 .

\section{Unidades territoriais de suscetibilidade natural identificadas}

$\mathrm{Na}$ área de estudo podemos distinguir seis unidades geomorfológicas diferenciadas, também, em termos dos processos perigosos naturais a que estão sujeitas (Figura 4, Quadro IV; Ramos et al., 2011a, b). No que se refere aos deslizamentos, pelas características litológicas, pelos declives e, de algum modo também pelos tipos de uso do solo, as unidades em que a suscetibilidade parece ser maior, serão as colinas areníticas e os núcleos diapíricos. Podemos distinguir seis unidades geomorfológicas diferenciadas em termos dos processos perigosos naturais a que estão sujeitas (Figura 4, Quadro IV; Ramos et al., 2011a,b).

\section{Discussão e Resultados}

De seguida mostram-se as matrizes de comparação (Quadros V, VI, VII, VIII e IX) e respetivos fatores de ponderação, obtidos para as características (critérios) consideradas importantes para a elaboração da carta de suscetibilidade a deslizamentos. Os critérios utilizados, por ordem de prioridade, foram, respetivamente: declive, litologia, uso do solo, fraturação, forma das vertentes e exposição das vertentes.

Com a finalidade de assegurar a qualidade dos dados obtidos foram construídas matrizes com as diferentes classes de um mesmo critério e, posteriormente, entre os diferentes critérios, as quais foram preenchidas por diferentes técnicos com experiência prática na temática dos deslizamentos: 2 Geólogos, 1 Engenheiro geólogo, 2 Engenheiros civis, 2 Geógrafos, 1 Engenheiro geógrafo.

Para todas as matrizes foi calculada a respetiva razão de consistência $(\mathrm{RC})$ e tidas em conta, apenas, aquelas cujo valor de $\mathrm{RC}<0,1$, tal como preconizado por SAATY (1991).

Quadro II

Escala proposta por SAATY (1991)

\begin{tabular}{|c|l|l|}
\hline $\begin{array}{c}\text { Intensidade de Importância } \\
\text { de cada característica }\end{array}$ & \multicolumn{1}{|c|}{ Definição } & \multicolumn{1}{|c|}{ Explicação } \\
\hline 1 & Mesma importância & Duas características contribuem igualmente para o objetivo \\
\hline 3 & Importância pequena de uma sobre a outra & $\begin{array}{l}\text { A experiência e o julgamento favorecem levemente uma característica em } \\
\text { relação à outra. }\end{array}$ \\
\hline 5 & Importância grande ou essencial & $\begin{array}{l}\text { A experiência e o julgamento favorecem fortemente uma característica em } \\
\text { relação à outra. }\end{array}$ \\
\hline 7 & Importância muito grande ou demonstrada & $\begin{array}{l}\text { Uma característica é fortemente favorecida; o seu grau de importância é de- } \\
\text { monstrado na prática. }\end{array}$ \\
\hline 9 & Importância absoluta & $\begin{array}{l}\text { A evidência favorece uma característica em relação a outra com elevado grau } \\
\text { de certeza. }\end{array}$ \\
\hline $2,4,6,8$ & Valores associados a julgamentos intermédios & Quando se deseja maior compromisso \\
\hline
\end{tabular}

Quadro III

Valores de CA em função da ordem da matriz

\begin{tabular}{|c|c|c|c|c|c|c|c|c|c|c|c|}
\hline $\mathrm{n}$ & 1 & 2 & 3 & 4 & 5 & 6 & 7 & 8 & 9 & 10 & 11 \\
\hline $\mathrm{CA}$ & 0 & 0 & 0,58 & 0,90 & 1,12 & 1.24 & 1,32 & 1,41 & 1,45 & 1,49 & 1,51 \\
\hline
\end{tabular}




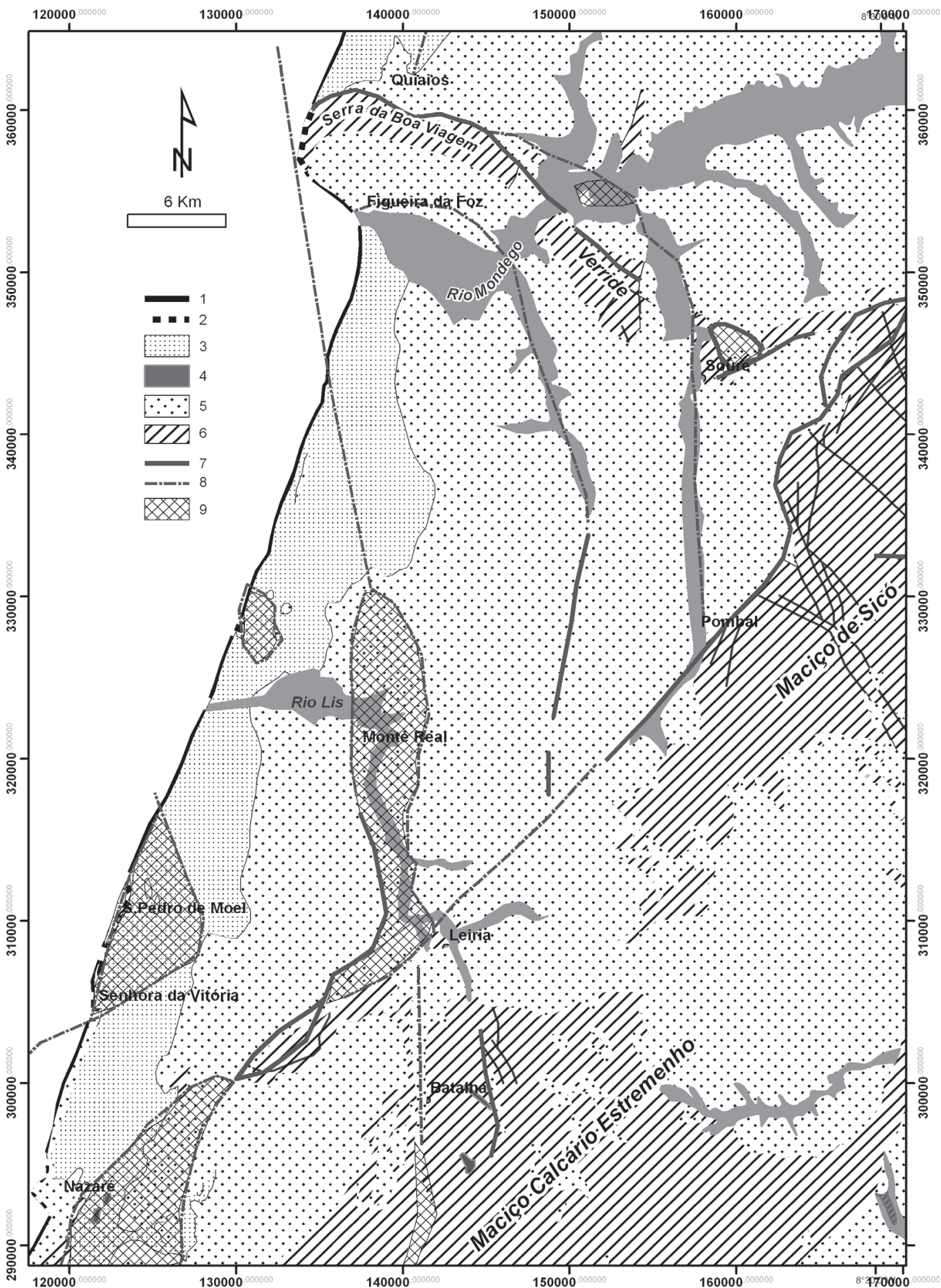

Figura 4

Distribuição dos diferentes domínios territoriais de suscetibilidade a processos perigosos naturais. 1 - Costa arenosa, 2 - Costa rochosa, 3 - Campo dunar, 4 - Planície aluvial, 5 - Colinas areníticas, 6 - Serras calcárias, 7 - Falhas, 8 - Falhas prováveis, 8 - Núcleos diapíricos. Fontes: Carta Geológica de Portugal, Instituto Geológico e Mineiro esc.1/500000; Carta Neotectónica de Portugal, esc. 1/1000000 (CABRAL e RibelRo, 1988); (RAmos et al., 2011a,b). 
Cartografia de suscetibilidade a deslizamentos e unidades territoriais de risco à escala regional: o caso da região Figueira da Foz - Nazaré

Quadro IV

Unidades territoriais e tipos de processos perigosos naturais associados

\begin{tabular}{|c|c|c|c|c|c|}
\hline Designação & Altitudes & Declives & Litologia & Uso do solo & Processos perigosos naturais \\
\hline Serras calcárias & $>400 \mathrm{~m}$ & Médios e elevados & Calcários & $\begin{array}{l}\text { Uso agrícola e florestal; } \\
\text { pastos; incultos }\end{array}$ & $\begin{array}{c}\text { Desabamento; Subsidência/abatimento; } \\
\text { Incêndios florestais }\end{array}$ \\
\hline Colinas areníticas & $20-200 \mathrm{~m}$ & Baixos e médios & Arenitos & Uso agrícola e florestal & $\begin{array}{l}\text { Deslizamentos, Fluxos, Erosão hídrica; } \\
\text { Incêndios florestais }\end{array}$ \\
\hline Planícies aluviais & $<20 \mathrm{~m}$ & Baixos & Aluviões & Uso agrícola & Inundação \\
\hline Planície litoral & $<20 \mathrm{~m}$ & Baixos & Dunas & Uso florestal & Incêndios Florestais \\
\hline Linha de costa/tipo de costa & $0 \mathrm{~m}$ & Baixos e elevados & Areias e Calcários & Actividades de lazer & Erosão costeira; Galgamentos \\
\hline $\begin{array}{l}\text { Alinhamentos tectónicos } \\
\text { ativos e núcleos diapíricos }\end{array}$ & Várias & Vários & Várias & Vários & Deslizamentos, Sismos \\
\hline
\end{tabular}

Quadro V

Cálculo da ponderação do critério "declive" através do método de compa-

ração par a par

\begin{tabular}{|c|r|r|r|r|r|c|}
\hline Classes declives $\left(^{\circ}\right)$ & \multicolumn{1}{c|}{$>30$} & $15-30$ & $5-15$ & $2-5$ & \multicolumn{1}{c|}{$0-2$} & Wi \\
\hline$>30$ & 1 & & & & & 0,37 \\
\hline $15-30$ & 0,50 & 1 & & & & 0,27 \\
\hline $5-15$ & 0,25 & 0,50 & 1 & & & 0,14 \\
\hline $2-5$ & 0,17 & 0,25 & 0,33 & 1 & & 0,07 \\
\hline $0-2$ & 0,11 & 0,14 & 0,25 & 0,33 & 1 & 0,04 \\
\hline
\end{tabular}

$\mathrm{RC}=0,03$

Quadro VI

Cálculo da ponderação do critério "litologia", através do método de comparação par a par

\begin{tabular}{|c|c|c|c|c|c|c|}
\hline Litologia & Margas & $\begin{array}{c}\text { Rochas arenosas } \\
\text { soltas }\end{array}$ & $\begin{array}{c}\text { Rochas arenosas } \\
\text { pouco consolidadas }\end{array}$ & \begin{tabular}{|c|} 
Rochas calcárias \\
pouco consolidadas
\end{tabular} & $\begin{array}{c}\text { Rochas } \\
\text { consolidadas }\end{array}$ & $\mathrm{Wi}$ \\
\hline Margas & 1 & & & & & 0,49 \\
\hline Rochas arenosas soltas & 0,50 & 1 & & & & 0,27 \\
\hline Rochas arenosas pouco consolidadas & 0,25 & 0,33 & 1 & & & 0,14 \\
\hline Rochas calcárias pouco consolidadas & 0,20 & 0,20 & 0,33 & 1 & & 0,07 \\
\hline Rochas consolidadas & 0,13 & 0,17 & 0,20 & 0,33 & 1 & 0,04 \\
\hline
\end{tabular}

$\mathrm{RC}=0,06$

Quadro VII

Cálculo da ponderação do critério "uso do solo" através do método de comparação par a par

\begin{tabular}{|c|c|c|c|c|c|c|c|}
\hline Uso do solo & Aterros & Áreas de Extração & Agricultura & Urbano & Floresta & Água & Wi \\
\hline Aterros & 1 & & & & & & 0,32 \\
\hline Áreas de Extração & 0,50 & 1 & & & & & 0,25 \\
\hline Agricultura & 0,33 & 0,33 & 1 & & & 0,10 \\
\hline Urbano & 0,50 & 0,50 & 3,00 & 1 & & 0,20 \\
\hline Floresta & 0,33 & 0,33 & 2,00 & 0,33 & 1 & 0,12 \\
\hline Água & 0,11 & 0,11 & 0,11 & 0,11 & 0,11 & 1 & 0,02 \\
\hline
\end{tabular}

$\mathrm{RC}=0,07$

Quadro VIII

Cálculo da ponderação do critério "forma das vertentes" através do método de comparação par a par

\begin{tabular}{|c|c|c|c|c|c|}
\hline Forma das vertentes & Côncavas & Retilíneas & Convexas & Planas & Wi \\
\hline Côncavas & $\mathbf{1}$ & & & & 0,50 \\
\hline Retilíneas & 0,50 & $\mathbf{1}$ & & & 0,31 \\
\hline Convexas & 0,25 & 0,33 & $\mathbf{1}$ & & 0,14 \\
\hline Planas & 0,11 & 0,14 & 0,20 & $\mathbf{1}$ & 0,04 \\
\hline
\end{tabular}

$\mathrm{RC}=0,05$ 
Quadro IX

Cálculo da ponderação do critério "exposição das vertentes" através do método de comparação par a par

\begin{tabular}{|c|c|c|c|c|}
\hline $\begin{array}{c}\text { Exposição das } \\
\text { vertentes }\end{array}$ & NE-NW & NE-SE & SE-SW & Wi \\
\hline NE-NW & 1 & & & 0,52 \\
\hline NE-SE & 2,00 & 1 & & 0,27 \\
\hline SE-SW & 3,00 & 2,00 & 1 & 0,21 \\
\hline
\end{tabular}

$\mathrm{RC}=0,01$

Quadro X

Cálculo da ponderação dos diferentes critérios através do método de comparação par a par

\begin{tabular}{|c|c|c|c|c|c|c|c|}
\hline Critérios & Declive & Litologia & Uso Solo & Fraturação & Forma & Exposição & Wi \\
\hline Declive & $\mathbf{1}$ & & & & & & 0,40 \\
\hline Litologia & 0,50 & $\mathbf{1}$ & & & & & 0,25 \\
\hline Uso Solo & 0,33 & 0,67 & $\mathbf{1}$ & & & & 0,12 \\
\hline Fraturação & 0,20 & 0,20 & 0,20 & 1 & & & 0,07 \\
\hline Forma & 0,20 & 0,20 & 0,17 & 0,50 & 1 & & 0,05 \\
\hline Exposição & 0,17 & 0,17 & 0,14 & 0,33 & 0,5 & 1 & 0,03 \\
\hline
\end{tabular}

$\mathrm{RC}=0,07$

Após a obtenção destas matrizes houve necessidade de relativizar o comportamento das diferentes classes, umas em relação às outras. Os pesos (Wi) que constam nas matrizes foram posteriormente indexados aos diferentes mapas em formato raster através da operação de reclassificação da extensão Spatial Analyst do software ArcGis9.3.

Construiu-se de seguida a matriz de comparação entre os diferentes critérios (Quadro X), bem como, o fator de ponderação de cada um deles, como determinante para a ocorrência de deslizamentos.

Recorreu-se então à álgebra de mapas como ferramenta para modelação cartográfica (TomLIN, 1991), obtendo-se desta forma o mapa de suscetibilidade a deslizamentos para a área entre a Figueira da Foz e a Nazaré (Figura 5).

\section{Conclusões}

Partindo do quadro IV, onde se individualizam diferentes unidades territoriais de risco, verifica-se que são os territórios definidos como colinas gresosas bem como as áreas afetadas por neotectónica e os núcleos diapíricos, as expectáveis para uma maior suscetibilidade a deslizamentos. Esta primeira individualização das unidades territoriais e a respetiva associação a diferentes tipos de processos perigosos naturais teve como base o conhecimento, no terreno, da área em termos dos critérios que foram tomados em conta como condicionantes: declive, litologia, uso dos solos, fraturação, forma das vertentes e exposição das vertentes.
A utilização do método de análise hierárquica (SAATY, 1991), para o cálculo das ponderações a atribuir a cada um dos critérios utilizados, mostrou resultados bastante fiáveis para a escala da área em análise. A sua associação ao método de modelação cartográfica utilizando a álgebra de mapas, recorrendo às ferramentas, já anteriormente descritas, do software ArcGis 9.3, permitiu a obtenção da carta de suscetibilidade a deslizamentos (Figura 5), onde se podem identificar dois grandes conjuntos com elevada suscetibilidade a deslizamentos. Um, de certa forma, circunscrito aos núcleos diapíricos com associação aos grandes acidentes tectónicos. De facto, nestes locais a litologia aflorante corresponde à Formação de Margas de Dagorda, de idade hetangiana, que devido à sua composição (margas gipsíferas) apresentam um comportamento plástico, deslizando facilmente quando em plano inclinado. 0 outro, localiza-se ao longo da costa arenosa, onde a associação de litologia arenosa, mesmo consolidada, aos elevados declives constituem os fatores determinantes do deslizamento.

Tanto num caso, como noutro, houve oportunidade de validação parcial do modelo no terreno. No caso das Margas de Dagorda, registámos os seus deslizamentos ao longo da Circular externa de Monte Real. No segundo caso, foi registado um deslizamento translacional na praia de Vale Furado.

Pretende-se continuar o registo de ocorrências, no terreno, a fim de otimizar a validação do mapa produzido, bem como o método a partir do qual foi gerado. 


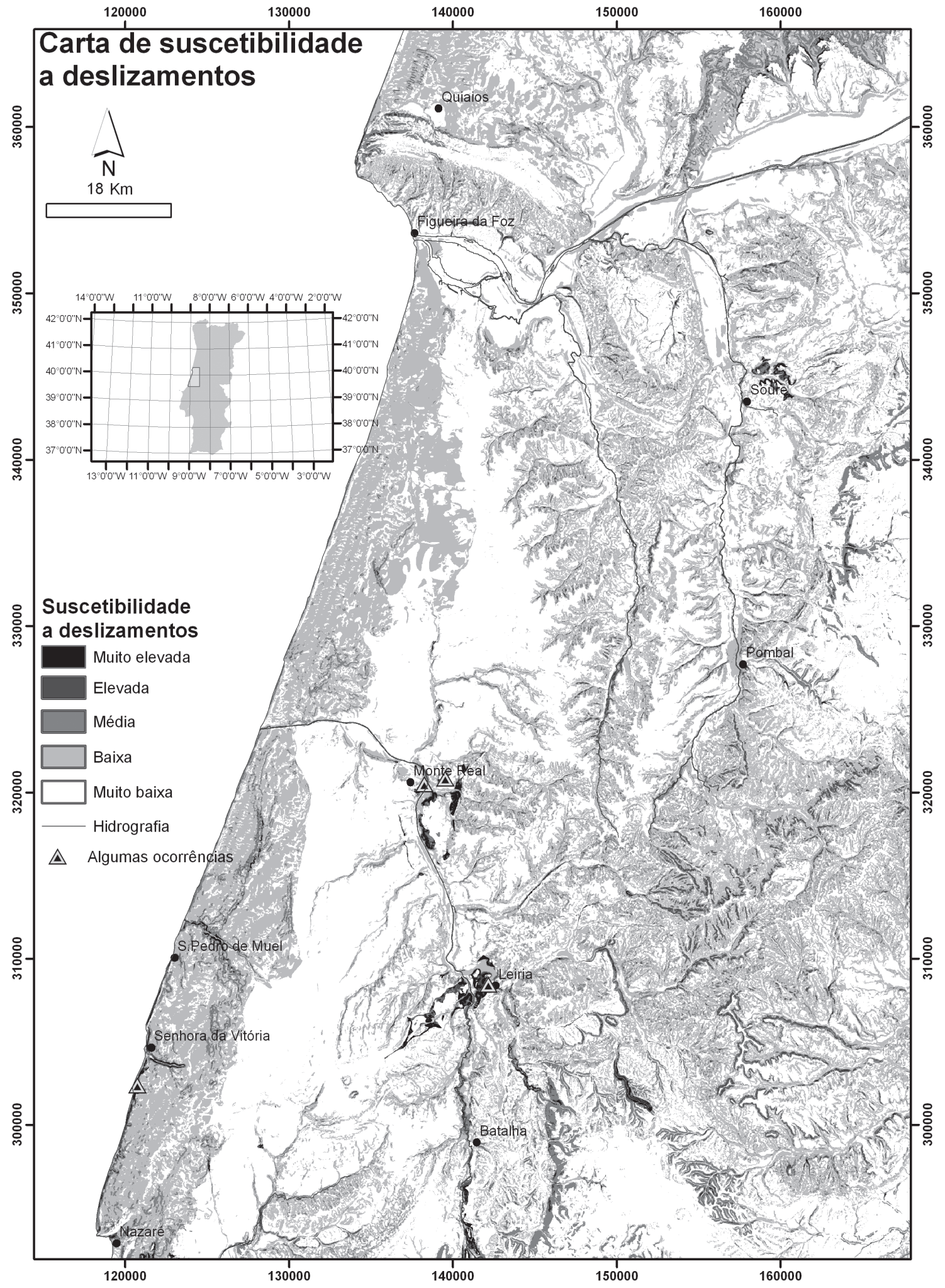

Figura 5

Carta de suscetibilidade a deslizamentos para a área entre a Figueira da Foz e a Nazaré. 


\section{Referências}

ABReu, U. A. V. (2007) - Riscos naturais no ordenamento do território: Aplicação ao município da Câmara de Lobos. Construção de um sistema de gestão ambiental em ambiente SIG. Dissertação de mestrado. Universidade de Coimbra. 208 p.

AlmeIDA, A. C. (1997) - Dunas de Quiaios, Gândara e Serra da Boa Viagem. Uma abordagem ecológica da paisagem, Colecção Textos, Faculdade de Ciências Sociais e Humanas, Lisboa, 321p.

Almeida, A. C.; Soares A. F.; Cunha L. e Marques, J. F. (1990) "Proémio ao estudo do Baixo Mondego". Biblos, LXVI, Coimbra, pp.17-47.

ANDRÉ, J. N.; CoRdeiro M.F. (2010) - "Intervenções antrópicas face ao recuo da linha de costa: exemplo da Foz do Douro à Nazaré". Actas do $V$ Congresso Nacional de Geomorfologia. Porto. CD-room, pp. 437-442.

Bachmann, A. e Allgöwer, B. (1999) - "The need for a consistent wildfire risk terminology" In Proceedings from the Joint Fire Science Conference and Workshop, Boise, Idaho, June pp.15-17.

Cabral, J. e Ribeiro, A. (1988) - Carta Neotectónica de Portugal. Serv. Geol. Portugal.

CorreiA, R. B. (2007) - Modelação cartográfica em ambiente SIG de suscetibilidade à erosão hídrica dos solos, caso da bacia da Ribeira dos Picos, Santiago (Cabo Verde). Tese de Mestrado. Universidade de Coimbra. 162 p.

Cunha, L. (1988) - As Serras Calcárias de Condeixa - Sicó - Alvaiázere. Estudo de Geomorfologia. Tese de Doutoramento. Faculdade de Letras. Univ. Coimbra, 329 p.

CunhA, L. (1990) - As Serras Calcárias de Condeixa-SicóAlvaiázere; Estudo de Geomorfologia. Col. Geografia Física, 1, Coimbra, 329 p.

CunhA, L. (1993) - "A paisagem cársica das Serras Calcárias de Condeixa-Sicó-Alvaiázere. Alguns argumentos a favor da sua protecção". Algar, 4, Lisboa, pp. 3-12.

CUnHA, L. (1997) - "Alguns problemas geomorfológicos no sector oriental do Baixo Mondego. 0 confronto de morfologias nas áreas de Coimbra e de Condeixa". Actas do Seminário "O Baixo Mondego - Organização Geossistémica e Recursos Naturais". Coimbra, pp. 41-49.

Cunha, L. e Gonçalves, J. M. A. (1994) - "Clima e tipos de tempo enquanto características físicas condicionantes dos riscos de incêncio. Ensaio metodológico". Cadernos de Geografi,. Coimbra, 13, pp. 3-13.

Cunha, L. e Dimuccio. L. (2002) - "Considerações sobre riscos naturais num espaço de transição. Exercícios cartográficos numa área a sul de Coimbra". Territorium, Coimbra, 9, pp. 37-51.
Cunha, P. P. (2002) - "Vulnerabilidade e risco resultante da ocupação de uma planície aluvial - o exemplo das cheias do rio Mondego (Portugal central)". Territorium, Coimbra, 9, pp. 13-35.

Cunha, P. P.; Silva, A. F.; André, J. N. e Cabral, M. C. (1997) "Considerações sobre a evolução actual do litoral entre a Figueira da Foz e Nazaré". In: Colectânea de ideias sobre a zona costeira de Portugal. Associação EurocoastPortugal (Ed.), Porto, pp. 489-502.

Cunha, P. P. e Dinis, J. L. (1998) - "A erosão nas praias do Cabo Mondego à Figueira da Foz (Portugal centro-oeste), de 1995 a 1998". Territorium, Coimbra, 5, pp. 31-50.

DRAOTC - Direcção Regional do Ambiente e do Ordenamento do Território do Centro, (2003) - O Litoral da Região Centro de Portugal - Um caso preocupante de Risco e de perda de Território, 38p.

DUDF- Direcção de Unidade de Defesa da Floresta (2011) Relatório anual de áreas ardidas e ocorrências em 2010. Autoridade Florestal Nacional, 31p.

Ferreira, A. Brum (1978) - "Planaltos e Montanhas do Norte da Beira - Estudo de Geomorfologia". Memórias do Centro de Estudos Geográficos, n 4, 379 p.

FerReiRA, A. Brum (1983) - "Problemas da evolução geomorfológica quaternária do noroeste de Portugal". Cuadernos do Laboratório Xeológico de Laxe, 5, pp. 311-332.

FigueIREDo, R. F. (2001) - Modelação cartográfica em ambiente SIG para apoio à decisão: aplicação ao estudo da afectação potencial de usos do solo no sector Norte do Maciço Marginal de Coimbra. Dissertação de Mestrado. Univ. Coimbra.

Julião, P. R.; Nery, F.; Ribeiro, J. L.; Branco, M.C. e Zêzere, J. L. (2009) - Guia metodológico para a produção de cartografia Municipal de risco e para a criação de sistemas de informação geográfica (SIG) de base municipal.

Lopes, F. C. (2005) - "A Figueira da Foz e a sua vulnerabilidade sísmica e de tsunami". Litorais, 3, pp. 7-14.

Lopes, F. C. (2006) - "Reflexões sobre a vulnerabilidade sísmica da Figueira da Foz". In: Lopes, F. C. e Callapez, Pedro (Coord.) - "As Ciências da Terra ao serviço do ensino e do desenvolvimento - o exemplo da Figueira da Foz". Kiwanis C. Figueira da Foz, pp. 3-10.

Lourenço, L.; Nunes, A.; Rebelo, F. (1994) - "Os grandes incêndios florestais registados em 1993 na fachada costeira ocidental de Portugal Continental”. Territorium. Coimbra, I, pp. 43-61.

Martins, A. F. (1949) - O Maciço Calcário Estremenho contribuição para um estudo de Geografia Física. Univ. Coimbra. 248 p.

Ramos, A. (2000) - Organização e significado dos depósitos mais recentes do estuário do rio Mondego. Dissertação de Mestrado. Univ. Coimbra, $200 \mathrm{p}$. 
Ramos, A.; Cunha, L.; Soares, A. F e Almeida A. C. (2001) - "Análise geomorfológica e estrutural da área envolvente do estuário do rio Mondego". Atas da V Reunião do Quaternário Ibérico. Lisboa.

Ramos, A. (2008) - O Pliocénico e o Plistocénico da plataforma litoral entre os palarelos do Cabo Mondego e da Nazaré. Dissertação de Doutoramento. Universidade de Coimbra. $329 \mathrm{p}$.

Ramos, A. M.; Cunha, L. S. e Cunha, P. P. (2011a) - "Diferenciação territorial e caracterização dos riscos naturais na área entre a Figueira da Foz e a Nazaré". Atas do VIII Congresso da Geografia Portuguesa, Lisboa. CD-Rom. 6 p. APG Edts.

Ramos, A. M.; Cunha, L. S. e Cunha, P. P. (2011b) - "Área da Figueira da Foz - Nazaré (Portugal central): Diferenciação espacial e caracterização de riscos naturais”. Atas do $13^{\circ}$ Congresso Brasileiro de Geologia de Engenharia. S. Paulo. CD-Rom. 10 p.

Rebelo, F. (2001) - Riscos naturais e acção antrópica. Imprensa da Universidade de Coimbra. 274 p. ISBN972-98225-7-3.

RibelRo, J. L. (2000) - Ordenamento territorial do estuário do Mondego. Conflitos, riscos ambientais e estratégias de gestão integrada. Seminário perspectivas de gestão integrada de ambientes costeiros. Associação Eurocoast-Portugal.departamento de Engenharia Civil da Universidade de Coimbra, pp.185-195.

Ribeiro, A.; Cabral, J.; Baptista, R. e Matias, L. (1996) - "Stress pattern in Portugal mainland and the adjacent Atlantic region, West Iberia". Tectonics, 15, pp. 641-659.

Rodrigues, M. L. (2007) - "O Património Geomorfológico e o Maciço Calcário Estremenho". Simp. Ibero-Am. sobre Patrim. Geol., Arqueol. e Min. em Regiões Cársicas, 28Jun.a 1 Jul.,Batalha, 2 p.

SAATY, T. L. (1977) - "A Scaling Method for Priorities in Hierarchical Structures". Journal of Mathematical Psycology, 15, 1977.

SAATY, T. L.(1991) - Método de Análise Hierárquica. São Paulo, McGraw-Hill, Makron.
SANTOS, P. M. P. (2009) - Cartografia de áreas inundáveis a partir do método de reconstituição hidrogeomorfológica $e$ do método hidrológico-hidráulico. Estudo comparativo na bacia hidrográfica do rio Arunca. Dissertação de mestrado. Universidade de Coimbra, $145 \mathrm{p}$.

TomLin, C. D. (1991) - "Cartographic Modelling. In: GoodCHILD, M.; MAguire, D. e Rhind, D. (Eds.) - Geographical Information Systems: Principles and Aplication. Harlow, Essex, UK: Longman Group, Ltd., pp. 361-370.

Zêzere, J. L. (2000) - A Classificação dos movimentos de vertente: Tipologia, Actividade e Morfologia. Apontamentos de Geografia-série investigação:6. CEG. Fac. Letras. Univ. Lisboa. 27 p.

Zêzere, J. L.; Reis, E; Garcia, R.; Oliveira, S.; Rodrigues, M. L.; Gonçalo, V. e Ferreira, A. B. (2004) - "Integration of spatial and temporal data for the definition of different landslide hazard scenarios in the área north of Lisbon (Portugal)". Natural Hazards and Earth System Sciences, vol. 4, European geosciences Union, p. 133-146.

Zêzere, J. L.; Pereira, A. R. e Morgado, P. (2006) - Perigos naturais e tecnológicos no território de Portugal Continental. Apontamentos de Geografia - Série Investigação, 19. Centro de Estudos Geográficos. Universidade de Lisboa.17 p.

\section{Cartografia de apoio:}

Carta Militar de Portugal, 1:25.000, folhas $n^{\circ} 227-B, 228,229$, 238-A, 239, 240, 248-B, 249, 250, 260, 261, 262, 272, 273, 274, 284, 285, 286, 296, 297, 298, 306-B, 307, 308, 309, 316, 317, 318 e 319, Instituto Geográfico do Exército, Lisboa.

Carta Geológica de Portugal, 1: 50.000, folhas n 19-A, 19-C, Serviços Geológicos de Portugal, Lisboa.

Carta Geológica de Portugal, 1:500.000, folha $\mathrm{n}^{\circ} 1$, Instituto Geológico e Mineiro, Lisboa, 1992. 